\title{
Erratum to: A new indicator for higher education student performance
}

\author{
Giada Adelfio $^{1}$ - Giovanni Boscaino ${ }^{1}$ - Vincenza Capursi ${ }^{1}$
}

(C) Springer Science+Business Media Dordrecht 2015

\section{Erratum to: High Educ (2014) 68:653-668 \\ DOI 10.1007/s10734-014-9737-x}

In the original publication of the article, the authors' given and family names were swapped inadvertently. The corrected author group is given in this erratum.

The online version of the original article can be found under doi:10.1007/s10734-014-9737-x.

Giovanni Boscaino

giovanni.boscaino@unipa.it

1 Dipartimento di Scienze Economiche, Aziendali e Statistiche, University of Palermo, viale delle Scienze, Edificio 19, 90128 Palermo, Italy 